\title{
Analysis of excitatory and inhibitory interactions at high temporal resolution in core circuits of the respiratory CPG
}

\author{
Yaroslav I Molkov*, Anke Borgmann²,3, Ruli Zhang ${ }^{3}$, llya A Rybak , Jeffrey C Smith ${ }^{3}$ \\ From Twenty First Annual Computational Neuroscience Meeting: CNS*2012 \\ Decatur, GA, USA. 21-26 July 2012
}

The pre-Bötzinger complex (pre-BötC) is the essential core component of the brainstem respiratory central pattern generator (rCPG) in mammals. Phasic excitatory and inhibitory synaptic inputs during the respiratory cycle are thought to dynamically shape membrane potential trajectories and spiking patterns of pre-BötC neurons. These synaptic inputs reflect the functionally interacting neuron populations involved in rhythm and inspiratory-expiratory pattern generation. The dynamic patterns of these synaptic inputs have not been systematically studied and characterized experimentally. Accurate temporal reconstruction of the synaptic input patterns is important for testing current models of the rCPG that incorporate specific excitatory and inhibitory circuit mechanisms for rhythm and pattern generation. A recent computational model of the rCPG generating a normal "three-phase" respiratory pattern [1] specified patterns of synaptic excitation and inhibition in the preBötC during the respiratory cycle required to produce the behaviorally distinct phases of inspiration (I) and two phases of expiration (E1, or post-inspiration, and E2). This model has not been rigorously tested by experimental data on dynamic changes in phasic postsynaptic excitatory and inhibitory conductances in different populations of pre-BötC inspiratory and expiratory neurons.

We developed analytical techniques that allow quantitative reconstruction of the patterns of synaptic conductances at high temporal resolution from intracellular recordings of membrane potential trajectories. Our approach extends previously proposed methods for

\footnotetext{
* Correspondence: ymolkov@iupui.edu

'Department of Mathematical Sciences, Indiana University - Purdue University Indianapolis, IN 46202, USA

Full list of author information is available at the end of the article
}

extracting dynamic patterns of synaptic input conductances $[2,3]$ and provides nearly continuous readouts of inhibitory and excitatory synaptic conductances in electrophysiologically different cell types throughout the respiratory cycle. The membrane potential trajectories of pre-BötC respiratory neurons were obtained by sharp microelectrode current-clamp recording within in situ perfused brainstem-spinal cord preparations of mature rats, which generate a three-phase respiratory pattern and provide mechanically stable conditions for intracellular recordings in functionally intact brainstem circuits.

We distinguished different types of inspiratory and expiratory pre-BötC neurons and analyzed the dynamical changes of excitatory (Ge) and inhibitory (Gi) conductances. Inspiratory neurons exhibited strong excitatory inputs (large dynamic increases in Ge) during their spiking phase followed by a wave(s) of inhibitory inputs during the expiratory period with large increases in Gi and temporal patterns consistent with two populations of inhibitory neurons providing inputs that coordinate inspiratory to expiratory and expiratory to inspiratory phase transitions. Expiratory neurons exhibited strong inhibition during the inspiratory phase, consistent with the rhythmic alternation of inspiration and expiration, and changes in Ge indicating reciprocal interactions between two major populations of inhibitory neurons coordinating the generation of two (E1 and E2) phases of expiration. The reconstructed patterns of $\mathrm{Ge}$ and $\mathrm{Gi}$ are generally consistent with previously proposed circuit architecture [1] and also suggest its extension. The techniques that we have developed for high temporal resolution of postsynaptic conductance changes are likely to have broad application for analysis of synaptic interactions in circuit components whenever intracellular recordings of membrane potentials can be 
obtained from functionally intact rhythmically active network.

\section{Acknowledgements}

This study was supported by NIH grants R01 NS057815, R01 NS069220, and the Intramural Research Program of the $\mathrm{NIH}$, NINDS.

\section{Author details}

${ }^{1}$ Department of Mathematical Sciences, Indiana University - Purdue University Indianapolis, IN 46202, USA. ${ }^{2}$ Zoological Institute, University of Cologne, Cologne, 50674, Germany. ${ }^{3}$ Cellular and Systems Neurobiology Section, NINDS, NIH, Bethesda, MD 20892, USA. ${ }^{4}$ Department of Neurobiology and Anatomy, Drexel University College of Medicine, Philadelphia, PA 19129, USA.

Published: 16 July 2012

\section{References}

1. Smith JC, Abdala AP, Koizumi H, Rybak IA, Paton JF: Spatial and functional architecture of the mammalian brain stem respiratory network: a hierarchy of three oscillatory mechanisms. J Neurophys 2007, 98:3370-3387.

2. Berg RW, Alaburda A, Hounsgaard J: Balanced inhibition and excitation drive spike activity in spinal half-centers. Science 2007, 315:390-393.

3. Endo T, Kiehn O: Asymmetric operation of the locomotor central pattern generator in the neonatal mouse spinal cord. J Neurophysiol 2008, 100:3043-54

doi:10.1186/1471-2202-13-S1-P39

Cite this article as: Molkov et al:: Analysis of excitatory and inhibitory interactions at high temporal resolution in core circuits of the respiratory CPG. BMC Neuroscience 2012 13(Suppl 1):P39.

\section{Submit your next manuscript to BioMed Central} and take full advantage of:

- Convenient online submission

- Thorough peer review

- No space constraints or color figure charges

- Immediate publication on acceptance

- Inclusion in PubMed, CAS, Scopus and Google Scholar

- Research which is freely available for redistribution

Submit your manuscript at www.biomedcentral.com/submit
Ciomed Central 